\section{$\underset{\substack{\text { hommes } \\ \text { \& migrations }}}{ }$}

\section{Hommes \& migrations}

Revue française de référence sur les dynamiques

migratoires

1305 | 2014

L'exil chilien en France

\title{
Quand les intellectuels français s'engagent
}

Entretien avec Alain Touraine

\section{Marie Lazaridis}

\section{(2) OpenEdition}

1 Journals

\section{Édition électronique}

URL : http://journals.openedition.org/hommesmigrations/2727

DOI : 10.4000/hommesmigrations.2727

ISSN : 2262-3353

Éditeur

Musée national de l'histoire de l'immigration

\section{Édition imprimée}

Date de publication : 1 janvier 2014

Pagination : 105-107

ISBN : 978-2919-040261

ISSN : 1142-852X

\section{Référence électronique}

Marie Lazaridis, «Quand les intellectuels français s'engagent », Hommes \& migrations [En ligne], 1305 | 2014, mis en ligne le 01 janvier 2017, consulté le 03 mai 2019. URL : http://

journals.openedition.org/hommesmigrations/2727; DOI : 10.4000/hommesmigrations.2727 


\section{LITTÉRATURE CHILIENNE HORS LES MURS}

par BERNARDO TORO, écrivain, rédacteur en chef de la revue Rue Saint Ambroise.

Les Chiliens le savent, leur pays est une île. De hauts murs le séparent du reste du monde. À ces barrières d'autres sont venues s'ajouter qui ont coupé le pays en deux. Je veux parler des murs bâtis par la dictature militaire. Cet épisode appartient désormais à l'Histoire. La démocratie est revenue au Chili depuis longtemps, l'exil politique s'est terminé, mais ces murs sont restés intacts pour des milliers de Chiliens. Deux tiers des exilés ont, en effet, décidé de ne plus retourner "chez eux". La politique a donc modifié la démographie du Chili et même sa géographie. Un nouveau territoire, ininscriptible, paradoxal, s'est ajouté au pays réel. C'est là que nous habitons. Sur les cartes ce territoire s'appelle la France ou la Suède ou le Canada, mais nous savons que ce n'est pas là son vrai nom, que nous mourrons sans avoir pu le nommer correctement. Cette étrange expérience où histoire, géographie et langue se confondent s'appelle exil. Sa résonance intime est difficile à saisir, et elle resterait définitivement inaudible sans le concours de la littérature.

Le titre de la présente introduction ${ }^{1}$ fait référence aux murs historiques qui ont conduit une page de la littérature chilienne à s'écrire hors du pays, mais aussi et surtout rappelle les murs plus subtils mais infranchissables que tout groupe humain oppose à la liberté du sujet. Cette mise sous surveillance du sujet n'est pas seulement le fait d'un pouvoir dictatorial, toute société, démocratique ou non, est répressive ; la survie du groupe repose toujours sur la contrainte du sujet. Si un pouvoir dictatorial peut, par contrecoup, stimuler la création littéraire, les murs qui contraignent le sujet produiront dans le meilleur des cas de la mauvaise littérature, c'est-à-dire une version affadie, simplifiée, et même falsifiée de l'expérience vécue. D'où la menace permanente qui guette l'écrivain, menace largement intériorisée qui le transforme bien souvent en son principal censeur. Il n'y a pas de pays où la littérature serait chez elle, pas de patrie où l'écrivain s'exprimerait librement, la censure sociale le poursuit partout, parfois en lui retirant ce qu'il possède, souvent en lui accordant ce dont il rêve, la plupart du temps en le laissant enchaîné à sa propre conscience. Rien ne muselle plus le sujet que sa propre conscience. Des chaînes morales, idéologiques, psychologiques, sexuelles l'attachent à un devoir de réserve qui, en contrepartie, lui assure une place stable dans la société. S'il se risquait à dire la vérité sur lui et sur le monde, il serait probablement banni. C'est dans cette mise sous tutelle 


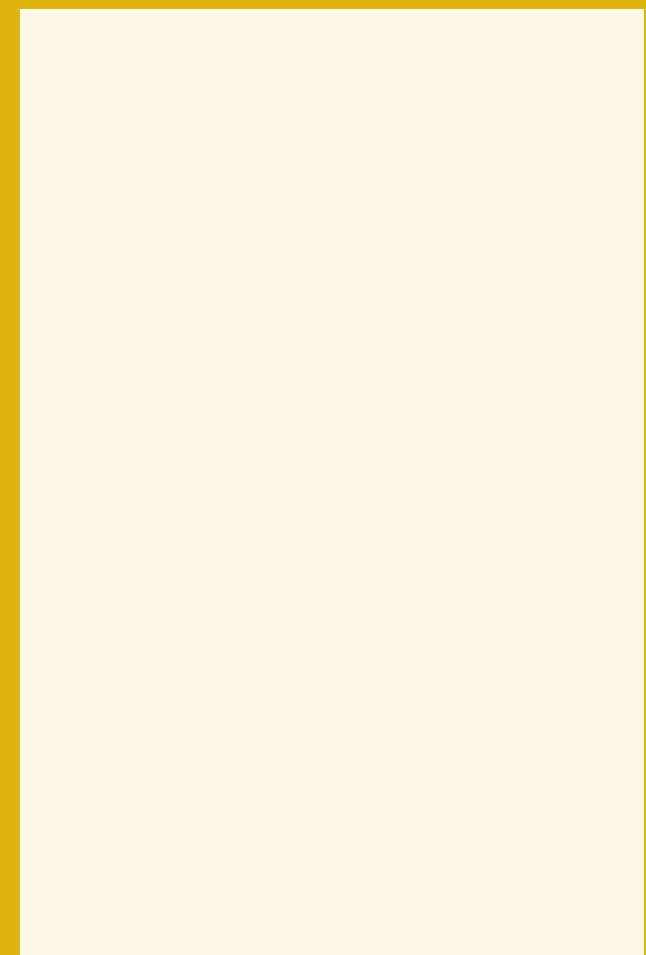

Revue Araucaria de Chile @ D.R.

du sujet que se noue le lien le plus profond entre littérature et exil.

L'histoire de la littérature chilienne hors des murs ne doit donc pas se résumer à la lutte des écrivains face à un pouvoir totalitaire. Cette lutte a été longue et cruelle, et mérite qu'on y revienne longuement, mais elle ne doit pas nous faire oublier la tension permanente qui oppose la communauté à l'écrivain, l'écrivain à lui-même. Une bonne partie de la littérature de l'exil nous parle de ces tensions, de ces conflits, de ces divisions. Le monde de l'exil se devait de rester uni et solidaire, les conflits devaient être réglés en interne ou passés sous silence, il ne fallait pas donner flanc aux critiques, l'ennemi était trop puissant. Certains écrivains ont néanmoins trahi ce pacte de silence en témoignant de la difficile insertion des individus (artistes ou pas) dans les communautés d'exilés et en dévoilant le pouvoir coercitif, dissuasif, répressif exercé par les représentants de ces communautés, prompts à condamner tout comportement et toute expression qui desservait leurs intérêts idéologiques. Si certains écrivains se sont sentis à l'étroit dans cette mise sous tutelle, d'autres, en revanche, ont mis leur écriture au service d'une cause qu'ils jugeaient plus importante que tout enjeu "littéraire". Mais la majorité ont oscillé entre ces deux positions, suivant les enjeux du moment, les circonstances historiques et leur évolution personnelle. Cette aventure littéraire hors des murs, ses péripéties, ses circonstances, ses conséquences, ses enjeux méritent d'être examinés de près.

\section{Contre l'étiolement du souvenir}

Ce dossier s'inscrit dans le cadre de la commémoration du quarantième anniversaire du coup d'État militaire. Comme tous les dix ans, toute une série d'activités sont organisées ici et là, et il faut reconnaître que celles du quarantième anniversaire manquent quelque peu de contenu. Tout se passe comme si nous n'avions plus rien de réellement nouveau à ajouter sur le sujet et que, devant ce vide, nous nous contentions de ressortir mécaniquement la même batterie de discours, d'images, de films, de chansons, afin d'accomplir notre devoir de mémoire décennal. Si longtemps la commémoration du coup d'État a été l'occasion de repenser l'événement à la lumière du présent et de puiser en lui le courage d'affronter les difficultés du moment, il est à craindre que désormais ces liens avec le présent se soient rompus et que cette commémoration se limite à rendre hommage aux morts et à rappeler 


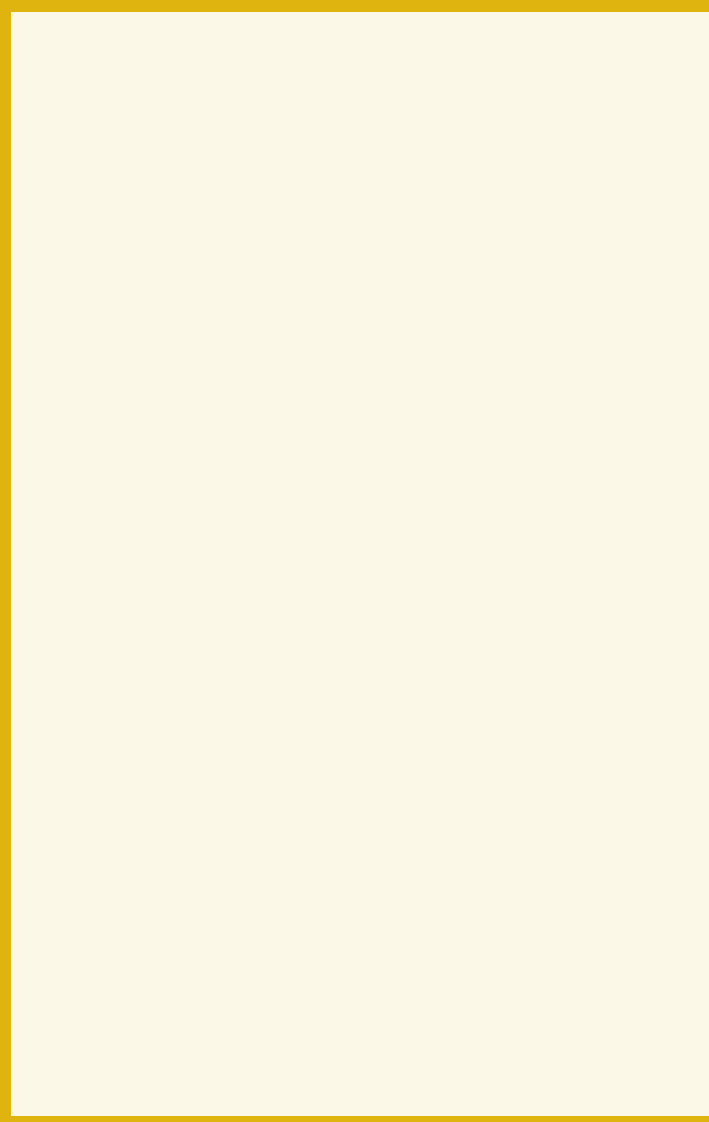

Revue Araucaria de Chile @ D.R.

leur destin tragique afin que de telles exactions ne puissent plus se reproduire.

À mon avis, cet étiolement du souvenir tient autant à une absence de perspectives politiques qu'à un changement de génération. Les exilés commencent peu à peu à quitter la scène et ce sont de plus en plus leurs enfants qui l'occupent. Cette relève générationnelle marque la fin d'un certain type de rapport à l'histoire, la fin d'un certain type de discours qui pendant quarante ans nous a tenu lieu de récit, d'explication et de mot de ralliement. Les discours qui ont fait vibrer les parents ne résonnent plus pareil aux oreilles des enfants. Il y a une crise de transmission entre les générations qui vide le souvenir de sa substance. Cette situation est propre à l'exil. Au Chili, ce quarantième anniversaire semble avoir suscité des réactions assez vives, des faits de violence, des contritions. Il s'agit là d'un fait nouveau. Traditionnellement, l'exil s'est toujours placé du côté de la mémoire, une mémoire, il faut bien le reconnaître, presque obsessionnelle, alors que le Chili de l'intérieur était mû par une nécessité d'oubli qui longtemps a frisé l'amnésie. Il ne serait pas juste de dire que les rôles se sont inversés et que l'exil s'est fatigué de se souvenir au moment où le Chili retrouve la mémoire. L'exilé est rivé au souvenir, la mémoire étant bien souvent son seul patrimoine, sa véritable demeure. La lassitude commémorative provient de certaines formes de discours, trop usées, qu'il est nécessaire de renouveler pour que cette mémoire puisse rester vivante et être transmise aux nouvelles générations. Nous pouvons envisager ce dossier autour de l'exil chilien comme une réponse à cette crise de transmission entre les générations. Il s'agit pour nous, en effet, d'une occasion privilégiée de faire connaître aux enfants une partie de l'histoire des parents qu'ils connaissent mal ou qu'ils ignorent, et, j'oserais dire, la partie qui touche de plus près la mémoire, puisque dans la littérature la question de la transmission est centrale.

Sans porter un jugement littéraire sur la production chilienne de l'exil, j'aimerais attirer l'attention sur la place qu'a occupée le livre au cours de ces années. Un rapport demandé par l'Unesco en 1989 a déterminé à 1700 le nombre de livres, revues, brochures publiés par les exilés chiliens entre 1973 et 1989 rien qu'en France. 1700 ouvrages. Il s'agit d'un nombre considérable et d'un fait unique dans l'histoire du Chili et même du monde, si l'on pense que les exilés chiliens en France n'ont jamais 


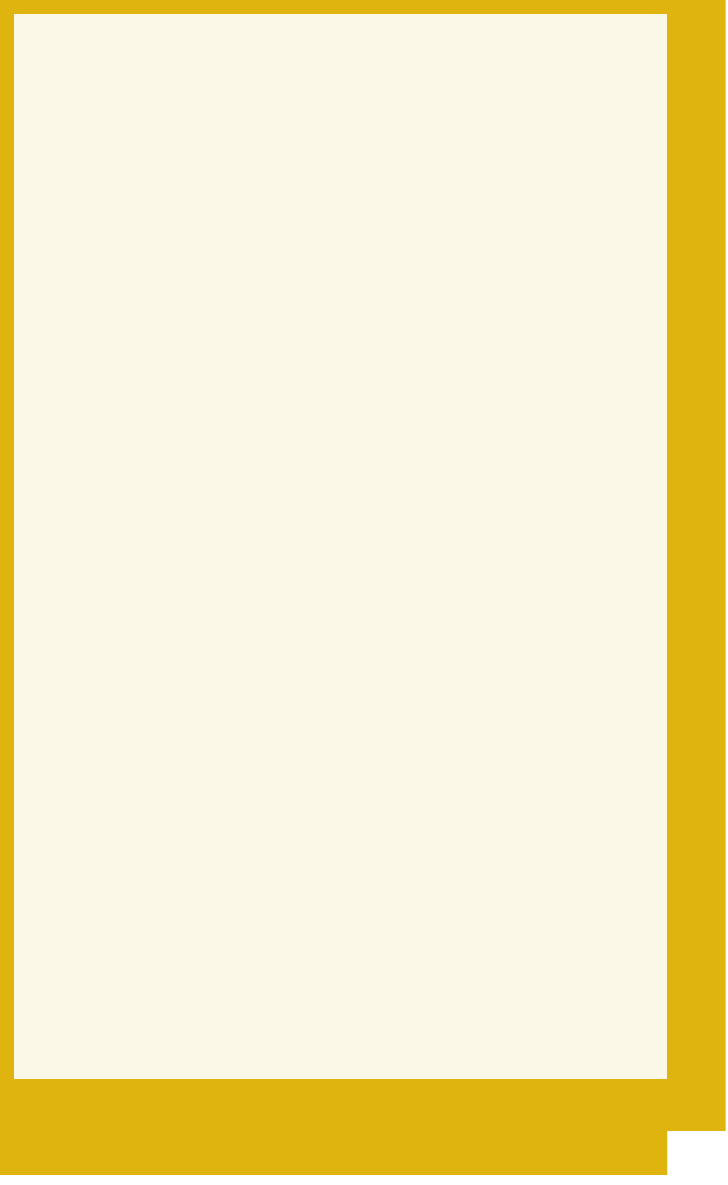

Revue Araucaria de Chile (c) D.R.

dépassé les 15 000. Cette hyperactivité artistique (le nombre de films et d'expositions de peinture a aussi été considérable) fait penser inévitablement aux républicains espagnols, mais aussi, plus paradoxalement, aux Russes blancs des années 1920, eux aussi portés par une rage créatrice qui a peu à peu cédé la place au désenchantement et au sentiment d'échec politique, eux aussi rongés par des divisions politiques et guerres intestines, avant que près de soixante ans plus tard, d'autres gens y découvrent leur extraordinaire apport à la littérature russe. J'espère que nous ne devrons pas attendre encore vingt ans avant de découvrir l'énorme apport de l'exil à la littérature chilienne. Qu'une communauté humaine accorde au livre une place aussi cardinale doit nous interpeller et nous faire réfléchir, surtout à une époque où l'importance du livre tend à s'amoindrir. Cette communauté d'intellectuels chiliens qui a été arrachée à son sol natal a trouvé dans l'écrit non seulement un instrument de lutte politique, mais aussi une sorte de territoire. C'est un fait culturel assez rare qui ne risque pas de se reproduire. Le peintre Roberto Matta disait que les exilés chiliens avaient livré une véritable "guérilla de l'esprit". Nous pouvons affirmer, sans trop nous tromper, que la période culturelle la plus florissante que le Chili ait connue dans toute son histoire s'est passée hors de ses frontières, en Europe, et en particulier en France entre 1973 et 1989. Jamais les Chiliens n'ont fait autant de films, écrit autant de livres, peint autant de tableaux, composé autant de chansons.

Le temps est venu de ressortir ces documents, de lire ces livres, de réexaminer ce patrimoine culturel. Nous découvrirons, bien sûr, beaucoup d'ouvrages de circonstance, beaucoup de documents politiques, mais aussi beaucoup de témoignages, de revues littéraires, de textes autobiographiques, de recueils poétiques et ô surprise une volonté très précoce de rendre compte par la fiction des faits qui venaient tout juste d'arriver (les années de l'Unité populaire et le coup d'État ), désir de fiction presque en direct que nous navons toujours pas retrouvé.

Quarante ans plus tard, au moment où se produit une véritable relève générationnelle entre les protagonistes de cette histoire et leurs enfants, il me paraît important d'accomplir ce devoir de mémoire, car, en définitive, ces textes constituent l'un des plus précieux héritages que les exilés laissent à leurs enfants. 